\title{
REDUCING THE ENERGY CONSUMPTION AND INCREASING THE EFFICIENCY OF PERISHABLE GOODS TRANSPORTATION BY REFRIGERATED VEHICLES ON URBAN ROUTES
}

\author{
D. ZAKHAROV ${ }^{1}$, E. MAGARIL ${ }^{2} \&$ P. KOZLOV ${ }^{1}$ \\ ${ }^{1}$ Tyumen State Oil and Gas University, Russia. \\ ${ }^{2}$ Ural Federal University, Russia.
}

\begin{abstract}
Inefficient operation of distribution networks in transportation reduces the profits of commercial enterprises and increases the cost of goods for people. Using ineffective methods of ensuring cargo preservation leads to deteriorating consumer properties of goods, increased fuel consumption and an increase in the amount of harmful emissions from car exhaust gases. This enhances the negative impact of transport on the environment, especially in major cities, which makes the problem of ensuring cargo preservation and improving transport efficiency relevant.

The objective of this work is to solve the problem of reducing the energy intensity of transportation and improving the efficiency of refrigerated vehicles in summer when delivering perishable goods (PGs) on urban routes.

Factors that impact the energy intensity of PGs transportation by refrigerated vehicles are presented. When assessing the efficiency of refrigerated vehicles operation, it is proposed to take into account weather and transport operating conditions. An approach is formed to assessing the efficiency of refrigerated vehicles considering operating costs, cargo preservation costs, transportation energy intensity.

Keywords: efficiency of transportation, energy consumption, fuel efficiency, perishable goods, refrigerated vehicles.
\end{abstract}

\section{INTRODUCTION}

Much of the food sold through the retail system requires compliance with the temperature storage conditions during transportation and sales and has a limited storage life.

It should be noted that even for a short product, if temperature increases, there is a reduction in its quality, since in this case physical-chemical, microbiological and biochemical processes start to develop which together cause undesirable changes in product quality influencing the safety of its use.

Product suppliers and trade organizations thus experience considerable losses, and unscrupulous retailers sell spoiled goods or compensate for their losses by increasing the cost of other goods.

Inefficient operation of transportation and increased transportation energy consumption is accompanied by an increase in emissions from the exhaust gases of cars. This has a negative impact on the environment, especially in large cities with lots of vehicles.

This problem is particularly acute for countries with warm and hot climate. Meanwhile, to date, there exists no integral approach to the selection and definition of the refrigerated vehicles management. This paper presents evidence-based techniques to solve this problem. 


\section{FEATURES OF PERISHABLE GOODS TRANSPORTATION BY REFRIGERATED VEHICLES ON URBAN ROUTES}

In Russia, as in many other countries having emerging economies, there are a significant number of small trading companies that have limited resources to store products requiring temperature control for preservation of goods. To ensure uninterrupted provision of public with goods such organizations place frequent orders with wholesale suppliers for small consignments. As a result, a small amount of perishable goods (PGs) at a subsequent shipment to a single retail outlet is delivered, not exceeding the capacity of frozen food storage chambers. This study examines transportation of deep-frozen products (for example, ice cream).

In order to reduce costs and improve vehicle efficiency, transportation of small-lot cargoes is performed on delivering-gathering routes. The route length and the number of discharge points are important factors in terms of transport vehicles operating conditions. When transporting PG on delivering routes with a large number of consignees, van doors must be frequently opened for unloading. This leads to a temperature change in the cargo compartment (CC) and non-compliance with the temperature conditions of $\mathrm{PG}$ transportation. Particularly, urgent is the problem of $\mathrm{PG}$ preservation during their transportation in summer.

Table 1 presents data on the duration of periods with positive air temperatures for Tyumen (Russia), a city located in one of the northern regions of Russia.

It should be noted that the length of such periods has significantly increased on average over the last decades due to global climate trends.

A large number of days with positive air temperature generate a need for refrigerated vehicles when delivering PG.

Using modern designs and materials in the manufacture of refrigerated vehicle bodies allows one to maintain the required temperature conditions for a long time when the $\mathrm{CC}$ doors are closed.

The influence of air temperature and travel time on the temperature conditions of the $\mathrm{CC}$ when its doors are closed is minimal.

At high air temperatures and prolonged unloading time, the amount of heat getting into the CC increases. To preserve PG, the heat coming into the $\mathrm{CC}$ must be compensated by cold produced by a refrigeration unit. This results in the increase in energy consumption (chemical energy of fuel or electricity) to maintain the required temperature.

An increase in the ambient air temperature and loading and unloading operation time leads to an increase in the $\mathrm{CC}$ temperature of the refrigerated vehicle and a reduction in the period of time during which the required temperature conditions are maintained [1,2].

Table 1: The number of days with positive ambient temperature for the climatic conditions of Tyumen.

\begin{tabular}{ll}
\hline Air temperature interval, ${ }^{\circ} \mathrm{C}$ & The number of days per year \\
\hline $0.1 \ldots \ldots+10$ & 77.3 \\
$+10.1 \ldots+20$ & 94.2 \\
$+20.1 \ldots+30$ & 29.4 \\
$+30 \ldots .+40$ & 0.1 \\
Total & 201 \\
\hline
\end{tabular}


To ensure preservation of PG during transportation on delivering routes with frequent stops for unloading in summer, it is more expedient to use refrigerated vehicles with a eutectictype refrigeration unit that are more adapted to such conditions, or perform a partial load of the refrigerated vehicle. Having thus provided cargo preservation, one must also solve the problem of reducing the energy intensity and improving the efficiency of vehicle operation.

\section{THE EFFICIENCY OF REFRIGERATED VEHICLES OPERATION}

\subsection{The energy intensity of the perishable goods transportation process}

The global market for road transport operates in a highly competitive environment. Transportation companies need to improve their competitiveness, including transportation cost saving. One way to reduce costs is to save fuel and energy resources by reducing the energy intensity and improving the transport efficiency. Reduction in the energy intensity of transport is determined primarily by the saved fuel and electricity.

The energy intensity of the transport process is determined by the amount of energy and fuel to be spent on implementation of the transport unit of work, and includes three components:

$$
E=E_{v m}+E_{g}+E_{p r}
$$

where $E$ - the energy intensity of transportation, $\mathrm{MJ} /(100 \mathrm{t} \cdot \mathrm{km}) ; E_{v m}$ - the energy consumption for the motor vehicle movement, $\mathrm{MJ} /(100 \mathrm{t} \cdot \mathrm{km}) ; E_{g}$ - the energy consumption to perform the transportation work when delivering goods, $\mathrm{MJ} /(100 \mathrm{t} \cdot \mathrm{km}) ; E_{p r}-$ the energy consumption to perform loading and unloading operations and preservation of cargo, $\mathrm{MJ} /(100 \mathrm{t} \cdot \mathrm{km})$.

In some cases, weather and climatic operating conditions have different effects on energy consumption. So, when transporting PG (frozen goods according to the classification of $\mathrm{PG})$ in summer, the energy consumption to move the vehicle $\left(E_{v m} \rightarrow \mathrm{min}\right)$ and perform the transportation work $\left(E_{g} \rightarrow\right.$ min $)$ is optimal. At the same time, the cost of providing cargo preservation $\left(E_{p r} \rightarrow\right.$ max $)$ increases significantly. On the other hand, in winter, the cost of providing cargo preservation $\left(E_{p r} \rightarrow 0\right)$ is minimal, while the vehicle movement $\left(E_{v m} \rightarrow \max \right)$ and the transportation work cost $\left(E_{g} \rightarrow \max \right)$ increases.

The need of accounting electric energy consumption is caused by an increasing number of electric vehicles, vehicles with hybrid power plants, as well as the use of electric energy to freeze plates of the eutectic-type refrigeration unit for PG transportation [1, 2]. For joint accounting of vehicle fuel efficiency and the amount of energy consumed and comparing the efficiency of using different types of transport (or fuel) the energy intensity indicator is used. The energy intensity for vehicles with the internal combustion engine and compressor-type refrigeration unit is determined by eqn (5):

$$
E=\frac{100 Q \delta \lambda}{W}
$$

where $E$ - the energy intensity of the transport process, MJ/100 t.km; $\delta$ - the fuel density, $\mathrm{kg} / \mathrm{dm}^{3} ; \lambda$ - the calorific fuel capacity, $\mathrm{kJ} / \mathrm{kg} ; Q$ - the fuel consumption, $1 ; W$ - the performed transportation work, $\mathrm{t} \cdot \mathrm{km}$.

The consumption of electricity to charge the eutectic plates in the refrigeration unit of the refrigerated vehicle is determined by eqn (6):

$$
E_{e}=\frac{360 P \tau_{c h}}{W}
$$


where $E_{e}$ - the electric energy consumption, MJ/100 t.km; $P$ - the power consumption when charging the eutectic plates of the refrigeration unit, $\mathrm{kW} ; \tau_{c h}{ }^{-}$the charging time (electrical connection), h.

The total energy consumption of the refrigerated vehicle with eutectic refrigeration equipment consists of the consumed fuel energy and the amount of electricity for charging the eutectic plates, eqn (7):

$$
E=\frac{100 \times Q \times \rho \times \lambda+3,6 P \tau_{c h}}{W} .
$$

\subsection{The fuel efficiency of refrigerated vehicles}

The fuel efficiency of refrigerated vehicles is estimated by the fuel economy according to the formula (8):

$$
q=\frac{100 Q_{r}}{l_{r}}=\frac{100\left(Q_{\text {dis }}+S \cdot \tau_{r}\right)}{l_{r}},
$$

where $q$ - the vehicle fuel economy, $1 / 100 \mathrm{~km} ; Q_{r^{-}}$the fuel consumption rate on route, $1 ; Q_{d i s}{ }^{-}$ the fuel consumption rate of the refrigerated vehicle with a disabled refrigeration unit, 1 ; $S$ - the sensitivity to increased fuel consumption by the operation time of the refrigeration unit, $1 / \mathrm{h} ; \tau_{r}$ - the refrigeration unit operation time, $\mathrm{h} ; l_{r}$ - the route length, $\mathrm{km}$.

The fuel consumption for PG preservation $\left(Q_{p r}\right)$ and the fuel economy are directly proportional to the refrigeration unit operation time. At this period, the frequency of crankshaft rotation in the refrigerated vehicle engine is increased.

Figure 1 illustrates the dynamics of fuel consumption of the refrigeration unit operation for a refrigerated vehicle GAZ-3717 when changing the duration of work.

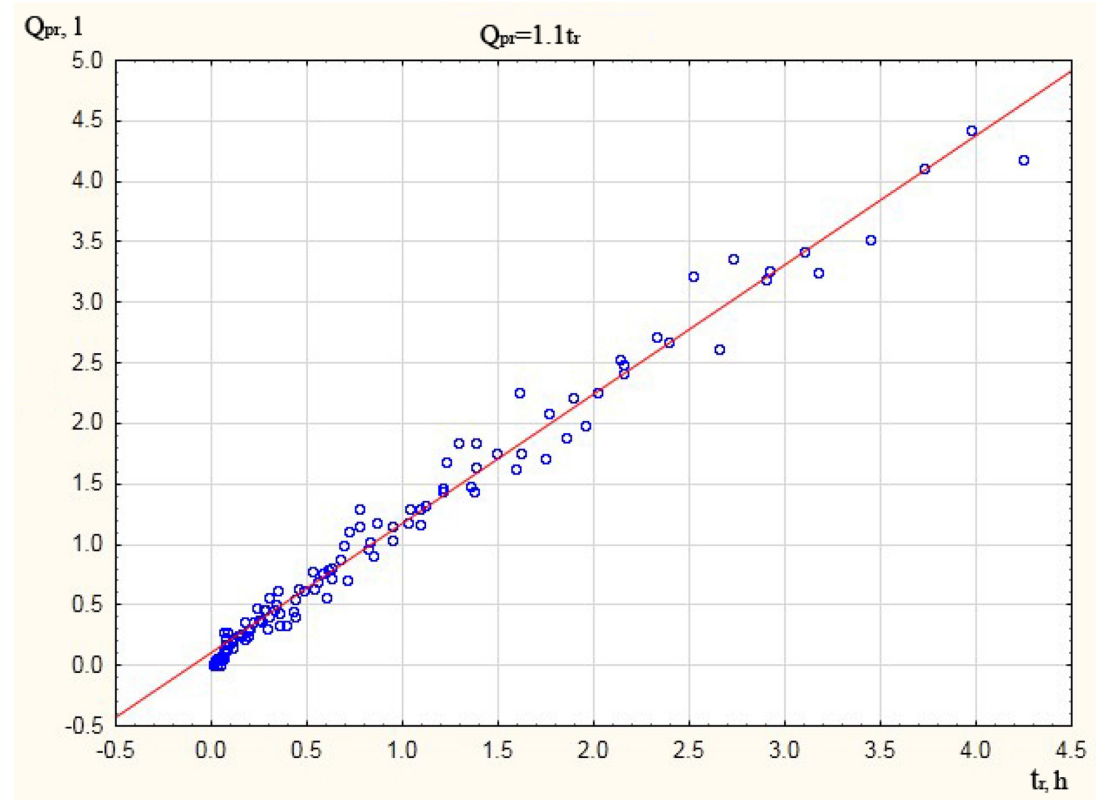

Figure 1: The dependence of the refrigeration unit fuel consumption on the operation time (refrigerated vehicle GAZ-3717). 
The operation time of the refrigeration unit depends on its performance and total heat input which enters the $\mathrm{CC}$ during unloading and which has to be compensated during movement:

$$
\tau_{r} \approx f\left(\Delta t_{a i r}, \tau_{u}, \tau_{t}, P\right),
$$

where $\tau_{r}$ - the refrigeration unit operation time, $\mathrm{h} ; \Delta t_{\text {air }}$ - the difference between the temperature of goods preservation and the ambient temperature, ${ }^{\circ} \mathrm{C} ; \tau_{u}-$ the total unloading time during which the heat exchange is possible through the open doors, $\mathrm{h} ; \tau_{t}$ - the total travel time over which the heat influx enters through the walls of the van, and the cooling capacity of the refrigeration unit, $\mathrm{h} ; P$ - the refrigeration unit performance, $\mathrm{kW} / \mathrm{h}$.

The maximum increase in fuel consumption for different refrigerated vehicles differs significantly: with a diesel engine $-4.51 / 100 \mathrm{~km}$, with a gasoline engine $-9.1 \mathrm{l} / 100 \mathrm{~km}$, for the engine running on natural gas $-12.77 \mathrm{l} / 100 \mathrm{~km}$. How the fuel type impacts its consumption is described in [3].

The reduction in the fuel consumption at the air temperature of $15^{\circ} \mathrm{C} \ldots 20^{\circ} \mathrm{C}$ (Fig. 2) is due to the reduction in the fuel consumption to move the vehicle under optimum conditions [4-8].

3.3 Ways to reduce the energy intensity of the transport process

The energy intensity of transportation and ways to reduce it depend on many factors that can be grouped as follows:

- Design factors (type of ICE and power plant);

- Organization and management factors (driver qualification, the system applied to adjust the fuel consumption rate of the vehicle based on the operating conditions);

- Process factors (route characteristics, transportation route optimization according to the criteria of distance and transportation cost, cargo preservation; selection of the rolling

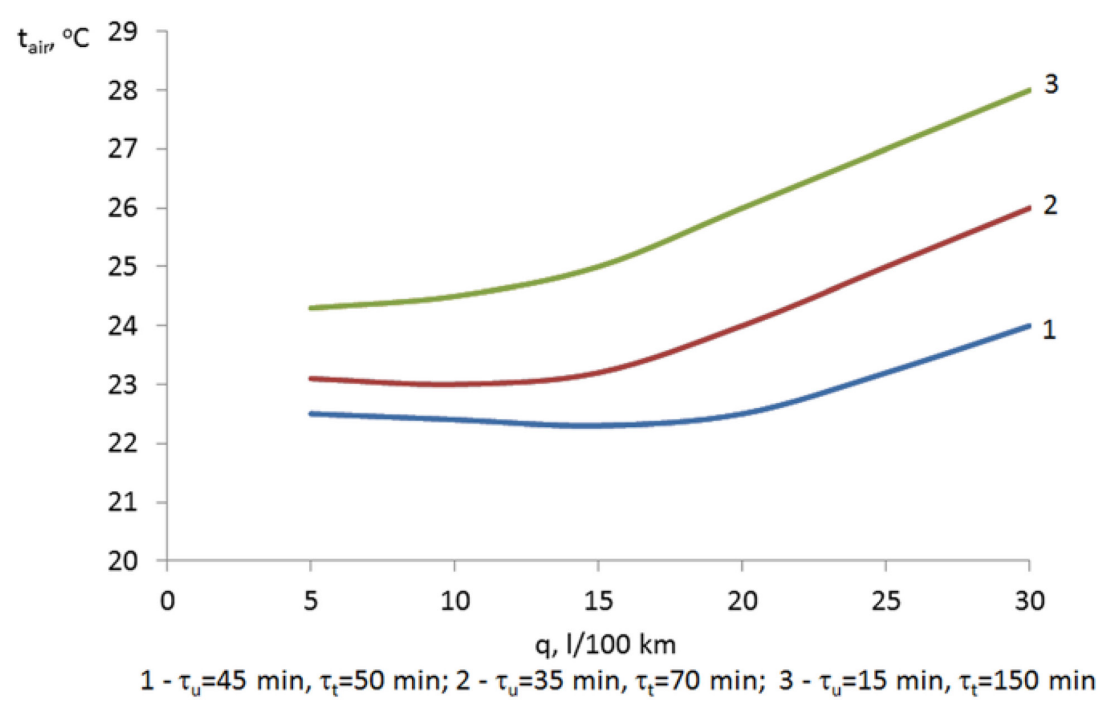

Figure 2: The impact of temperature on fuel consumption by vehicle GAZ-3717. 
stock (RS) make and model most adapted to the transportation conditions and cargo preservation, optimal loading of the vehicle CC taking into account cargo preservation; using optimal fuels for the transportation conditions).

To reduce the cost of PG transportation, the energy intensity of transportation must be reduced for refrigerated vehicles (Table 2).

With increasing air temperature, the lowest energy intensity of transportation corresponds to the refrigerated vehicle IVECO 59-12. Accordingly, the choice of a vehicle should be made taking into account the anticipated temperature conditions.

The calculation results of the energy intensity of the transport process on urban delivering routes are shown in Table 3 . When the air temperature is $+10^{\circ} \mathrm{C}$, the lowest energy intensity of transportation is observed in GAZ-3717 working on gas fuel.

\subsection{Evaluation of the operational efficiency of refrigerated vehicles when transporting perishable goods}

Evaluation of the transportation energy efficiency is conditioned by the need to relate the resulting effect in the form of the saved fuel and electricity and the costs to achieve this effect. The costs include purchasing vehicles, replacing refrigeration units, repairing equipment. When there is a small effect and considerable costs to achieve it, the payback period should be compared with the possible performance life of the rolling stock.

Table 2: Ways to reduce the energy intensity of PG transportation.

\section{Type of energy consumption}

Measures

Energy consumption - Improving the design of the internal combustion engine and for the motor vehicle power plant;

movement $\left(\mathrm{E}_{\mathrm{mv}}\right)$ - Differential correction of fuel consumption rates (an objective Energy consumption to determination of the norm) considering the operating conditions; perform the transporta- Selection of the rolling stock make and model most adapted to tion work $\left(\mathrm{E}_{\mathrm{g}}\right)$ (deliver- the transportation conditions;

tion work $\left(\mathrm{E}_{\mathrm{g}}\right)$ (deliver- - Transportation route optimization according to the criteria of ing goods) distance and transportation cost, as well as traffic irregularity conditions;

- Ensuring the application of fuels optimal for the transportation conditions, namely, summer, winter or arctic grades of diesel fuel in accordance with the temperature conditions, the use of gasoline and diesel fuels with modifying additives that reduce the specific consumption $[9,10]$.

Energy consumption - Selection of the rolling stock model most adapted to cargo presfor cargo preservation ervation;

$\left(\mathrm{E}_{\mathrm{pr}}\right)$

- Developing the optimal route according to the criteria of cargo preservation;

- Determining the optimal loading of the vehicle CC. 
Table 3: The energy intensity of PG transportation*.

\begin{tabular}{|c|c|c|c|c|c|c|c|c|c|}
\hline Indicators & \multicolumn{3}{|c|}{$\begin{array}{l}\text { GAZ-3717 } \\
\text { (gasoline) }\end{array}$} & & \multicolumn{2}{|c|}{$\begin{array}{l}\text { GAZ-3717 } \\
\text { (gas fuel) }\end{array}$} & \multicolumn{3}{|c|}{$\begin{array}{l}\text { IVECO 59-12 } \\
\text { (diesel fuel) }\end{array}$} \\
\hline $\begin{array}{l}\text { Fuel consumption, } \\
1 / 100 \mathrm{~km}\end{array}$ & 17.4 & & & 19.2 & & & 15.5 & & \\
\hline Fuel density, kg/l & 0.735 & & & 0.55 & & & 0.769 & & \\
\hline $\begin{array}{l}\text { Calorific value capac- } \\
\text { ity of fuel, } \mathrm{MJ} / \mathrm{kg}\end{array}$ & 44.0 & & & 45.2 & & & 43.1 & & \\
\hline $\begin{array}{l}\text { Ambient air tempera- } \\
\text { ture, }{ }^{\circ} \mathrm{C}\end{array}$ & 10 & 20 & 30 & 10 & 20 & 30 & 10 & 20 & 30 \\
\hline $\begin{array}{l}\text { Working time of the } \\
\text { refrigeration unit, } h\end{array}$ & 0 & & & 0 & & & 6 & 9 & 12 \\
\hline $\begin{array}{l}\text { Total mileage of one } \\
\text { motor vehicle per } \\
\text { shift, km }\end{array}$ & 84 & 168 & 168 & 84 & 168 & 168 & 84 & 84 & 84 \\
\hline $\begin{array}{l}\text { Fuel consumption per } \\
\text { shift, } 1\end{array}$ & 16.2 & 32.4 & 32.4 & 18 & 36 & 36 & 13 & 13 & 13 \\
\hline Time on route, $\mathrm{h}$ & 8.7 & 13.3 & 13.3 & 8.7 & 13.3 & 13.3 & 8.7 & 8.7 & 8.7 \\
\hline $\begin{array}{l}\text { Number of hauls per } \\
\text { shift }\end{array}$ & 1 & 2 & 2 & 1 & 2 & 2 & 1 & 1 & 1 \\
\hline $\begin{array}{l}\text { Energy consumption, } \\
\mathrm{kW}\end{array}$ & 0 & 0 & 0 & 0 & 0 & 0 & 19.2 & 28.8 & 38.4 \\
\hline $\begin{array}{l}\text { Energy intensity of } \\
\text { transportation, } \mathrm{MJ} / \\
\mathrm{t} \cdot \mathrm{km}\end{array}$ & 416 & 832 & 832 & 355 & 710 & 710 & 396 & 424 & 452 \\
\hline $\begin{array}{l}\text { Energy intensity of } \\
\text { transportation, } \mathrm{MJ} / \mathrm{kg}\end{array}$ & 0.35 & 0.44 & 0.44 & 0.3 & 0.60 & 0.6 & 0.33 & 0.36 & 0.38 \\
\hline
\end{tabular}

*The volume of traffic per day $-1.5 \mathrm{t}$, the length of the route $-84 \mathrm{~km}$. The compressor capacity of the eutectic refrigeration unit IVECO $59-12$ is $3.2 \mathrm{~kW} / \mathrm{h}$.If the ambient temperature is changed from $10^{\circ} \mathrm{C}$ to $30^{\circ} \mathrm{C}$ the charging time of cold accumulators increases from 6 to $12 \mathrm{~h}$.

When planning a short-term work (2-3 years), the implementation of measures to reduce the energy intensity of transportation for the company becomes unprofitable. If the company has long-term contracts with the manufacturer (supplier) of goods for transport services, the implementation of measures for energy efficiency becomes feasible. It is also necessary to assess the efficiency of rolling stock operation.

The efficiency of the motor vehicle use is assessed according to the energy intensity and the cost of transportation, operation, preservation of cargo, quality of transport services and other 
indicators. When choosing a rolling stock, a number of conditions are taken into account: the energy intensity of transportation, the efficiency of vehicle operation considering the cost of fuel, electricity, maintenance and repairs, car reliability. Issues relating to the provision of preservation, reduction of the energy intensity of PG transportation by refrigerated vehicles and conservation of ecology are discussed in many works [1, 2, 11-19].

When transporting ice cream on delivering routes to the retail network in summer, the travel time over which the temperature conditions of transportation are maintained in the $\mathrm{CC}$ of the refrigerated vehicle with the compressor-type refrigeration unit is less than the actual running time on route. To ensure cargo preservation, the carrier divides the con-

Table 4: The economic efficiency of refrigerated vehicles operation*.

\begin{tabular}{|c|c|c|c|}
\hline Indicators & $\begin{array}{l}\text { GAZ-3717 } \\
\text { (gasoline) }\end{array}$ & $\begin{array}{l}\text { GAZ-3717 } \\
\text { (gas fuel) }\end{array}$ & $\begin{array}{c}\text { IVECO } \\
59-12 \\
\text { (diesel fuel) }\end{array}$ \\
\hline Rated load capacity, tons & 1.2 & 1.2 & 2.1 \\
\hline $\begin{array}{l}\text { Rolling stock's capacity utilization rate (load } \\
\text { capacity) }\end{array}$ & $\begin{array}{l}0.62 \\
(0.4)\end{array}$ & $\begin{array}{l}0.62 \\
(0.4)\end{array}$ & $\begin{array}{l}0.71 \\
(0.95)\end{array}$ \\
\hline Motor vehicle purchase cost, rubles & $1,100,000$ & $1,150,000$ & $2,850,000$ \\
\hline Travel time, $\mathrm{h}$ / number of hauls per shift & $6.65 / 2$ & $6.65 / 2$ & $8.66 / 1$ \\
\hline Performance per haul, $t /$ boxes & $0.75 / 200$ & $0.75 / 200$ & $1.5 / 400$ \\
\hline Number of motor vehicles for transport & 2 & 2 & 1 \\
\hline $\begin{array}{l}\text { Total distance covered by one motor vehicleper } \\
\text { shift, km }\end{array}$ & 168 & 168 & 84 \\
\hline Operation costs, rubles $/ \mathrm{km}$ & 16.19 & 12.88 & 16.99 \\
\hline Cost per $1 \mathrm{~h}$ of operation, rubles/h & 272 & 218 & 254 \\
\hline Total transportation costs, rubles & 6376 & 5094 & 3627 \\
\hline Profit from transportation, rubles per day & 104 & 1386 & 2853 \\
\hline Profitability of transportation, $\%$ & 1.6 & 27 & 78 \\
\hline $\begin{array}{l}\text { Economic efficiency of investments, rubles / } \\
\text { rubles }\end{array}$ & 0.02 & 0.29 & 0.24 \\
\hline Discounted costs, rubles & 3156 & 3791 & 2055 \\
\hline Payback period, years & 40 & 3.5 & 3.8 \\
\hline
\end{tabular}

$*$ Calculation is performed for the conditions: average speed of movement $V_{a v}=18 \mathrm{~km} / \mathrm{h}$, route length $\mathrm{l}_{\mathrm{r}}=84 \mathrm{~km}$, quantity of cargo per day $\mathrm{Q}_{\text {day }}=1.5 \mathrm{t}$, total loading time $\mathrm{t}_{\text {loading }}=0.12$ $\mathrm{h}$, total unloading time $\mathrm{t}_{\text {unloading }}=1 \mathrm{~h}, 25$ unloading points on route, Revenue from transport activities -6480 rubles. 
signment into 2-3 parts and transports the goods in parts. This significantly increases the vehicle operating time on route and transportation costs. Using liquefied natural gas as fuel for refrigerated vehicles would greatly reduce operating costs, due to its much higher calorific value compared to liquid petroleum fuels, and low cost. To reduce the specific consumption of gasoline and diesel fuels, it is advisable to use fuel additives that increase the energy efficiency of vehicles operation $[9,10]$. It should be noted that these measures also make it possible to significantly improve the environmental performance of vehicles.

Using refrigerated vehicles with eutectic refrigeration units leads to extra costs for electricity needed for 'charging' the cold accumulators.

Performance indicators of the rolling stock on delivering routes when transporting ice cream in Tyumen (at the ambient temperature of $+30^{\circ} \mathrm{C}$ ) are shown in Table 4 .

Analysis of the results shows that the use of specialized vehicles complying with certain conditions of goods transportation leads to an increase in the efficiency of the company and its competitiveness. To reduce costs for purchase of the rolling stock carriers acquire IVECO refrigerated vehicles with low mileage.

Due to their high manufacturing quality, these vehicles can be used on delivering routes for a long time without repairs and replacement.

\section{CONCLUSION}

The theoretical and experimental studies of the effect of transport and weather conditions of refrigerated vehicles operation on the transport energy intensity and efficiency allowed the authors to develop recommendations on the selection of the rolling stock and preservation of, as well as techniques for practical use.

It was found that at ambient temperatures up to $+10^{\circ} \mathrm{C}$ to transport ice cream on delivering routes, it is more appropriate to use refrigerated vehicles with a compressor-type refrigeration unit working on gas fuel. At air temperatures above $+10^{\circ} \mathrm{C}$ to ensure preservation of goods that can be delivered to the consignee without deterioration, it is necessary to determine the optimal amount of transportation and the length of the route. If it is impossible to ensure cargo preservation by optimizing the routing and volume of traffic, it is worthwhile to replace the compressor-type refrigerated vehicle with the eutectic-type one.

The developed techniques allow us to calculate the optimal loading of the refrigerated vehicle and the delivering route characteristics, as well as determine the objective fuel consumption rate of the refrigerated vehicle.

Applying the developed techniques in practice makes it possible to reduce mileage and fuel consumption when the compressor-type refrigerated vehicles are replaced with the eutectic-type ones.

\section{ACKNOWLEDGEMENT}

This research was supported by Act 211 Government of the Russian Federation, contract № 02.A03.21.0006.

\section{REFERENCES}

[1] Sidorov, S.A., Adaptability of refrigerated vehicles for transportation of perishable goods: Synopsis of diss. ...cand. oftehn. Sciences [in Russian], TSOGU: Tyumen, 2011.

[2] Sidorov, S.A., Rational use of refrigerated vehicles for transportation of perishable goods at different operation conditions [in Russian]. Automotive Enterprise, 9, pp. 30$32,2010$. 
[3] Anisimov, I., Ivanov, A., Chikishev, E., Chainikov, D. \& Reznik, L., Assessment of gas cylinder vehicles adaptability for operation at low ambient temperature conditions. WIT Transactions on Ecology and the Environment, 190, pp. 685-695, 2014. http://dx.doi.org/10.2495/EQ140651

[4] Reznik, L.G., Index of the vehicle operating conditions severity [in Russian]. Izvestiavyssihucebnyhzavedenij. Neft i gaz, 2, pp.112-115, 2000.

[5] Zamboni, G., André, M., Roveda, A. \& Capobianco, M., Experimental evaluation of heavy duty vehicle speed patterns in urban and port areas and estimation of their fuel consumption and exhaust emissions. Transportation Research Part D: Transport and Environment, 35, pp.1-10,2015.

http://dx.doi.org/10.1016/j.trd.2014.11.024

[6] Ehsani, M., Ahmadi, A. \& Fadai, D., Modeling of vehicle fuel consumption and carbon dioxide emission in road transport. Renewable and Sustainable Energy Reviews, 53, pp. 1638-1648, 2016. http://dx.doi.org/10.1016/j.rser.2015.08.062

[7] Van Der Voort, M.C. \& Van Maarseveen, M.F.A.M., Reducing fuel consumption and emissions in urban areas by using a new fuel-efficiency support tool. Advances in Transport, 8, pp. 631-640, 2001.

[8] Zhu, X., Garcia-Diaz, A., Jin, M. \& Zhang, Y., Vehicle fuel consumption minimization in routing over-dimensioned and overweight trucks in capacitated transportation networks. Journal of Cleaner Production, 85, pp. 331-336, 2014. http://dx.doi.org/10.1016/j.jclepro.2013.10.036

[9] Magaril, E., The influence of carbonization elimination on the environmental safety and efficiency of vehicle operation. International Journal of Sustainable Development and Planning, 8(2), pp. 231-245, 2013. http://dx.doi.org/10.2495/SDP-V8-N2-231-245

[10] Magaril, E., Increasing the efficiency and environmental safety of vehicle operation through improvement of fuel quality. International Journal of Sustainable Development and Planning, 10(6), pp. 880-893, 2015.

http://dx.doi.org/10.2495/SDP-V10-N6-880-893

[11] Zakharov, D.A., Sidorov, S.A. \& Kozlov, P.A., Reducing energy consumption and increasing the efficiency of transport of perishable goods refrigerated vehicles [in Russian], TSOGU: Tyumen, p. 120, 2016.

[12] Tassou, S.A., De-Lille, G. \& Lewis, J., Food transport refrigeration. Brunel University Centre for Energy and Built Environment Research School of Engineering and Design, 2012.

[13] Marshall, R., Lawton, R. \& Lawson, I., Energy Usage During Refrigerated Transport, Technical document prepared for the School of Engineering and Design, Brunel University, 2006.

[14] Chatzidakis, S.K. \& Chatzidakis, K.S., The impact on energy consumption and environmental pollution due to insufficient terms of the international ATP agreement for the carriage of perishable foodstuffs. ECOS 2006 - Proceedings of the 19th International Conference on Efficiency, Cost, Optimization, Simulation and Environmental Impact of Energy Systems, eds C.A. Frangopoulos, C.D. Rakopoulos \& G. Tsatsaronis, National Technical University of Athens: Greece, pp. 1337-1343, 2006.

[15] TRANS/WP.11/2000/9: Economic Commission for Europe, Inland Transport Committee, Working Party on the Transport of Perishable Foodstuffs (Geneva, 30 October-2 November 2000), Comment to Annex 1, Appendix 2, paragraph 29 
Transmitted by the expert from Denmark Online,available at: http://www.unece.org/ trans/main/wp11/wp11doc/2000/ wp110009e.pdf

[16] James, S., New technology in food cooling. International Journal of Refrigeration, 19, pp. 76-77, 2005.

http://dx.doi.org/10.1016/0140-7007(96)89564-8

[17] Spence, S.W.T., Doran, W.J., Artt, D.W. \& McCullough, G., Performance analysis of a feasible air-cycle refrigeration system for road transport. International Journal of Refrigeration, 27, pp. 381-388, 2005.

http://dx.doi.org/10.1016/j.ijrefrig.2004.08.005

[18] Chatzidakis, S.K. \& Chatzidakis, K.S., Refrigerated transport and environment. International Journal of Energy Research, 28(10), pp. 887-897, 2004.

http://dx.doi.org/10.1002/er.1002

[19] Koehler, J., Tegethoff, W.J., Westphalen, D. \& Sonnekalb, M., Absorption refrigeration system for mobile applications utilizing exhaust gases. International Communications in Heat and Mass Transfer, 32(5), pp. 333-340, 1997.

http://dx.doi.org/10.1007/s002310050130 